\title{
On the Continuing Education from the Perspective of MOOCs
}

\author{
Li LI \\ School of Foreign Languages \\ Shanghai University of Political Science and Law, Shanghai, China
}

Keywords: MOOCs, Continuing education, Teaching.

\begin{abstract}
How to combine continuing education with MOOCs effectively is still a puzzle. To solve this problem, the article first discusses the influence of MOOCs on the teaching in the continuing education, and then studies the teaching reform from the perspective of MOOCs. Accordingly, a new teaching model of continuing education based on MOOCs is put forward, which consists of teaching objective, teaching process and teaching assessment. This new model contributes to putting their strong points together so as to achieve the goal of playing their advantages to the full and having better results in the continuing education.
\end{abstract}

\section{Introduction}

Massive Open Online Course (MOOC), as a new online education model, has become more and more popular. MOOCs are mostly free online courses presented via the web and available for anyone, anywhere. In 2011 and 2012, for-profit organizations, such as Udacity, edX, and Coursera, worked with universities, colleges, and other partners to launch numerous MOOCs that registered hundreds of thousands of students, and caught the imagination of many more [1]. On the different provider platforms, a rich variety of MOOCs are available to a very large number of students. In fact, with its remarkable and exceptional advantages, MOOC attracts an increasing number of higher schools and learners. Continuing education is certainly not an exception, for its participant groups are more complex and diverse. That is to say, these leaners in continuing education do not vary in age composition and learning time, but also in their leaning ability, skill requirement, etc. MOOC is in full possession of the huge potential of satisfying the demands of students.

MOOCs are the new "magic bullet" that transforms access to, and costs of, higher education and, maybe, show the way in which lifelong learning - always part of the educational dream - could become a reality [2]. As a new form of teaching, MOOC is superior to traditional teaching method in its flexibility and effectiveness, which does good to meeting the individual needs of the continuing education and also brings challenges and opportunities to the transformation of teaching methods in continuing education.

\section{The Influence of MOOCs on the Teaching in the Continuing Education}

\section{Enhance the Influence of the Continuing Education}

MOOC has a significant impact on the informatization and internalization of the continuing education. With the Internet, massive open online courses are provided for leaners so as to increase the opportunities of furthering their education, deepen the reform of courses and teaching models in the continuing education and better the quality of personnel training, which is also a critical problem that the continuing education currently cope with[3]. MOOCs are online courses, which not only 
enhances its reputation and social influence, but also helps those continuing education colleges in remote areas to optimize their resources and structure of teaching staff. Apparently, in the long run, university geographic boundaries will blur.

\section{Contribute to the Innovation of the Continuing Education}

MOOC tends to stimulate the innovative cooperation between different continuing education colleges and also between the continuing education colleges and government, enterprises or other social organizations [4]. Its innovation not only lies with peer interaction, forum and auto-assessment but also with the possibility of realizing the good dream that everyone enjoys the opportunity to continue their education by means of MOOCs, because a large amount of online courses are currently granted free of charge and only a small number of online courses are obtained for relatively low fee, which reduces the cost of the continuing education to the minimum. All of these is beneficial to the balanced development of education and is also vital to promote education equity.

\section{Promote the Reform of Teaching Model and Teaching Method}

Teaching in the MOOCs does not refer to the one in the traditional class any longer. Teachers are more like a leader in the discussion. Textbooks are not needed by the teachers in MOOCs anymore, because MOOCs present a more vivid, specific and straightforward illustration about what the students are going to learn and can also "take" students to the real factory and workshop so that leaner's can see the latest instruments and devices[5]. Teachers don't even spend much time answering learners' questions, because MOOC has a distinct feature of interaction that any leaner in any part of the world may give them instant answers. What's more, there are more learners to revise and complement these answers, if necessary. MOOCs provide interactive forums enabling students to interact with each other as well as with their professors and teaching assistants (TA). The quizzes of the course can reflect learners' state timely. According to Big Data, solutions to the problem that leaner's have to deal with can be put forward. In this case, the student-centered teaching model can be actually realized.

\section{The Study on the Teaching Reform from the Perspective of MOOC}

If MOOCs are linked with the continuing education smoothly, a new teaching model will be formed by combining several teaching models such as MOOCs, online courses, face-to-face courses, etc. In the process of combination, three main points are worth studying, listed as follows.

\section{Study on the Transform of Teachers' Role}

Teachers and students are two parts in the teaching. While students are the main body of the class, teachers play a predominant role in the traditional class. Teachers' guidance is the basis and premise for students to achieve their goal. In the teaching, teachers should work hard to guide students, so as to get them be involved in learning process, learn to probe, be interested in studies, and learn to learn independently. And ultimately students try to turn the still knowledge from books into dynamic ability. Actually, teachers play multiple roles in the whole teaching process: They are knowledge conveyers, supplying students language knowledge and skills; they are helpers, helping students obtain information and analyze it, and helping students to learn and solve problems; they are organizers, organizing activities for students; and they are controllers, making sure students are disciplined in the classroom...... 
However, MOOCs bring about great changes in teaching model, especially in the continuing education. MOOCs enable thousands of people to study together, which can engender a scale effect. Under such circumstance, it is possible to invite experts in other fields to complete the teacher's projects together, such as the TAs, experts on courseware design, teaching designer, art designer and so on. This process will contribute to the diversification and the professionalization of teacher groups[6]. At the same time, some teachers will also have the psychological sense of "loss" without doubt when they have to be TAs instead of professors. MOOCs accelerate the differentiation of university teachers.

\section{Study on the Reform of Teaching Manage ment and Administration}

MOOCs provide the ordinary universities with a good chance to become competent at the design of some difficult courses. They can also cooperate with other universities to form a teaching community, which indicates that when a teacher gives a lecture at one university, students could simultaneously "attend" this course in different places. Students can even study on the different platforms of MOOC directly, and get the credits through official examinations. To some degree, the teaching-testing separation will be achieved. What's more, if Flipped Class Model could also be utilized, the innovation of teaching model will achieve a complete success.

In traditional universities, the classes are basically taught by their own teachers, but MOOC and other systems would possibly socialize the process of "non-core teaching". It is more likely for students in the continuing college to make more choices from these online courses. For example, it will not be necessary for some universities to set up the department of public basic courses or other similar departments, because their students could "attend" those courses taught by professors from other universities. It may help some teachers to achieve professional development, and it can also make the organization focus on the core affairs [6]. This great change in the teaching and learning is worth great concern of administrators in the continuing education. Accordingly, they have to work out practical plans to adapt themselves to the new circumstances.

With the help of Big Data, Learning analytics and other advanced technique, we can make analyses of those massive data in the learning process. In this way, the hidden principle might be discovered, and we can provide some specific suggestions for students. As a result of the data, the traditional assessment mode by plain experiences and numbers could be changed [6]. Besides the benefits for the learning process, those technologies could also help to specify the administrative management, and thereby it will bring about a revolutionary change to the school management.

\section{Study on the Teaching Assessment Method}

MOOC supplies abundant teaching resources for the learners in the form of online resources sharing. As long as anyone can register on the platform of MOOCs, he/she is able to gain free access to most of MOOCs. It gives full play to the initiative, autonomous learning, because learners' are free to plan their study schedule, arrange their time for study.

However, in reality, for adults students in the continuing education college may not have enough time to arrange for study. Meanwhile, they usually have a strong purpose of receiving continuing education and expect much as well. If there is no effective assessment system and the process of study is completely in the charge of the students, the teaching process is hard to trace and the teaching effect is not guaranteed. In addition, there exists the matter of honest. Because cheating is endemic and no viable 
solution has yet proven to be effective. No reliable way of measuring what students learned exists. So people question the real value added to these courses. All these problems mention in the above is contradicted to the teaching model of MOOC. Teachers have to adapt themselves to the transformation from summative assessment to diagnostic assessment of different stages. That is, in the usual process of study, teachers are aware that they must trace their students' study schedule on the platform of MOOCs. If necessary, teachers have to give them a hand in terms of difficult points. Meanwhile, teachers have to summarize and analyze students' state and intensify the follow-up assessment of students' involvement in the discussion of the MOOCs. Certainly, students are encouraged to act actively in concert with teachers to fill in their logs, record their study notes, and so on. Diagnostic assessment of different stages enables students to persist in their offline study.

\section{A New Teaching Model of Continuing Education Based on MOOCs}

According to the above analysis, MOOC is a perfect complement to continuing education. Students in the continuing education college are mostly adults who have to do their own jobs, so they don't have adequate time to attend face-to-face class. MOOCs just make up for its shortage because of its flexibility in time. Students can be free to arrange their own time to take online courses. However, lack of effective supervision in the teaching of MOOC, students tend to be lazy or can't complete their learning task on time. This problem can be settled by means of contact hours and course assessment in the traditional continuing education class. Hence, the paper puts forward a new teaching model of continuing education on the basis of MOOC, shown in Figure1. That is, face-to-face instruction is still dominant in the whole process of teaching, while MOOC gradually is used to instruct students' self-study. The new teaching model contributes to putting their strong points together so as to achieve the goal of playing their advantages to the full and having better results in the continuing education.

\section{Teaching Objective}

The core of the new teaching model is teaching objective. Features vary from course to course. To achieve different teaching objectives, it is sure to have different teaching approaches and processes. When the teaching objectives are set in the model, it is necessary to take it into consideration that continuing education and MOOC have their own features respectively. Only thus, will the objectives be workable.

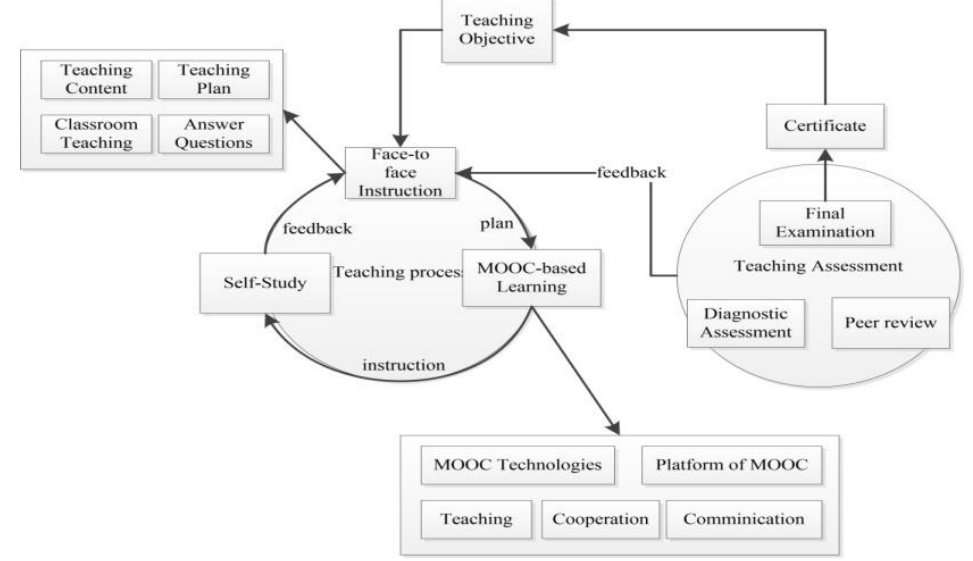

Figure1.A new teaching model of continuing education based on MOOCs 


\section{Teaching Process}

Teaching process refers to the specific activities of achieving the teaching objectives. In the model, teaching process mainly includes classroom teaching, take online courses on the platforms of MOOC, self-study.

Classroom Teaching. Comparatively speaking, contact hours in continuing education courses are limited, which are mainly used to complete teaching plan, give students further explanation about major points and difficult points in the teaching and help students solve some problems in their self-study. With the introduction of MOOC in the teaching, explanation about course content and most of problems students come across in the learning can be dealt with. Thus, teachers can set aside enough time to focus on teaching planning and some problems that are too difficult for students to solve on the Internet.

Studying on the Platform of MOOC. This mainly refers to the students' study outside classroom teaching, which is the extension of face-to-face instruction. Online courses help students to study the main points and difficult points which used to be presented in the classroom teaching, which provides teachers with more possibilities of guiding students to study roundly and systematically as to their courses. Compared with the continuing education model of "classroom teaching + self-study", the new model of "classroom teaching +MOOCs +self-study" is more systematic and able to enhance the teaching effect of continuing education strikingly.

Self-study. Self-study in the model refers to student's autonomous study in the guidance of classroom teaching and MOOCs. In the model of "classroom teaching +self-study", self-study is a main period of teaching, occupying most time of a course( for example, generally, the ratio between classroom and self-study is 1:3, even up to $1: 4$ in some colleges). It takes a long time for students to meet with their teachers in the class, so the process of self-study has to face the reality of lack of effective instruction, which results in low efficiency in their study and lowers the teaching quality as well. However, the new model of "classroom teaching +MOOCs +self-study" is more systematic and cut down part of the content that students have to learn by themselves. In addition, self-study can be partially completed with the help of MOOCs. Teachers can communicate effectively with students online and students themselves can help each other by group discussion in MOOCs. So self-study in the new model is not entirely self-study in the traditional way, which contributes to enhancing the efficiency of their study and teaching quality as well.

\section{Teaching Assessment}

Teaching assessment is not only used to evaluate teaching effect but also viewed as an important means to promote teaching. For example, planning the examination courses enables students to work hard so as not to fail in the course, which is an important means to urge students to complete the course. Teaching assessment in the new model not only includes such traditional teaching assessment as final examination, but also other assessment approaches such as diagnostic assessment, peer review, etc. The combination of these assessment forms can promote teaching and enhance the percentage of completing MOOCs as well.

\section{Conclusions}

Most of the MOOCs are accessible for free and as thus they give everyone the chance to educate themselves and move forward in their careers. Obviously, MOOCs have a tremendous influence on the continuing education. But because of its particularity, 
including resources, technology, theory, teachers, continuing education has to currently deal with many problems in the implement of MOOC. Therefore the present teaching system of the continuing education has to face in-depth reform and develop a new teaching model by combining effectively with MOOCs.

\section{Acknowledge ments}

This research was financially supported by Continuing Education College of Shanghai University of Political Science and Law.

\section{References}

[1] D. Adair, S. W. Alman, D. Budzick, et al., Many Shades of MOOCs, Internet Learning Journal, 2014, 3(1).

[2] Information on http://www.moocs.com.

[3] Sheng-jun Gao, Qi Li, Zhi-rui Zhao, How continuing education to cooperate with MOOC-The way to solve working-learning problem in continuing education. Journal of HUBEI Correspondence University.2015, 28(16): 25-26.In Chinese.

[4] Wei-yu Chen, New opportunities of strategic transformation for the continuing education brought by MOOC, Adult Education. 2015 (2): 9-12.In Chinese.

[5] J. G. Mazoue. The MOOC model: Challenging traditional education, 2014.

[6] Jun-jie Shang, Education Process Reengineering: MOOC and Reform of Higher Education. Beijing Forum (2013) the harmony of civilizations and prosperity for all---retrospect and prospect, 2013, 201(3): 1.In Chinese. 